\title{
Better Learning Through History: Using Archival Resources to Teach Healthcare Ethics to Science Students
}

\author{
Dr. Julia R.S. Bursten \\ University of Kentucky \\ Department of Philosophy \\ jirbursten@uky.edu \\ 1415 Patterson Office Tower \\ Department of Philosophy \\ University of Kentucky \\ Lexington, KY 40506 \\ And \\ Matthew Strandmark \\ University of Kentucky \\ University of Kentucky Libraries \\ mstrandmark@uky.edu \\ Margaret King Library \\ University of Kentucky \\ Lexington, KY 40506
}

\section{ETHICAL STATEMENT:}

- Funding: Neither author has any funding to declare

- Conflict of Interest: Not Applicable

- Ethical approval: The University of Kentucky Institutional Review Board exempted this from review after determining that this study qualified as a "non-novel Quality Assurance/Quality Improvement project." This ruling was decided on May 24, 2021.

- Informed consent: Not Applicable

\section{Abstract}

While the use of archives is common as a research methodology in the history and philosophy of science (HPS), training in archival methods is more often encountered as part of graduatelevel training than in the undergraduate curriculum. Because many HPS instructors are likely to have encountered archival methods during their own research training, they are uniquely positioned to make effective pedagogical use of archives in classes comprised of undergraduate 
science students. Further, because doing this may require changing the way HPS instructors think about the aims and varieties of archival research, archivists themselves can be valuable resources in developing archives-based learning activities for science students in HPS classrooms. In this article, we describe an archives-based learning activity developed for a population of primarily pre-medical students in a healthcare ethics class and discuss the pedagogical benefits of this activity. This activity was developed via a collaboration between an HPS instructor (Bursten) and an education archivist (Strandmark). Our hope is that this discussion may serve both as a proof of concept for the use of archives-based learning activities as tools for teaching HPS to science students, and as an argument for the unique benefits that archival engagement can impart to science students.

\section{Introduction}

While the use of archives is common as a research methodology in the history and philosophy of science (HPS), training in archival methods is more often encountered as part of graduatelevel training than in the undergraduate curriculum. Such training, further, is usually carried out with the aim of developing students' abilities to generate new HPS scholarship. However, recent pedagogical research (Sharron and Cotton 2011; Morgan and Yakel 2013; Brown, Losoff, and Hollis 2014; Beam and Schwier 2018; Gray 2020) has shown that archives can offer access to learning activities that combine (a) information literacy with (b) critical thinking while (c) placing students in unique settings that can raise the stakes of their engagement. Developing skills (a) and (b) is especially important for science students, and these are often the sorts of competencies that lead science students to seek out HPS instruction. Because many HPS instructors are likely to have encountered archival methods during their own research training, they are uniquely positioned to make effective pedagogical use of archives - that is, to design educational experiences that accomplish (c)_in classes comprised of undergraduate science students. Further, because doing this may require changing the way HPS instructors think about the traditional preconceptions of how archival research and archival documents can be used in their courses, archivists themselves can be valuable resources in developing archives-based learning activities for science students in HPS classrooms.

In this article, we describe an archives-based learning activity (ABLA) developed for a population of primarily pre-medical students in a healthcare ethics class and discuss the pedagogical benefits of this activity. This activity was developed via a collaboration between an HPS instructor (Bursten) and an education archivist (Strandmark). Our hope is that this discussion may serve both as a proof of concept for the use of archives-based learning activities as tools for teaching HPS to science students, and as an argument for the unique benefits that archival engagement can impart to science students. We proceed as follows: In Section 2, we describe the student population and learning objectives of the course, with emphasis on how elements of course design serve the class's population of primarily science majors. In Section 3, we introduce readers to contemporary pedagogical research on $A B L A s$ and the changing educational roles of archivists within university settings. In Section 4, we describe the ABLA we 
developed, which consisted of students engaging with historical medical research records and producing reports on the ethical problems indicated by these records. Section 5 uses summaries of student feedback to discuss ways in which the ABLA impacted student learning, and Section 6 offers concluding reflections.

This collaboration, and the course that it supports, take place at a large public research university in the United States. This institutional setting aided the collaboration, as Bursten and Strandmark were part of the same institution. Some of our successes, and some of our challenges, are particular to our setting —chief among these is the specific medical records that generated our ABLA. However, we hope and believe many of our remarks will be useful for educators across a variety of geographical and institutional settings.

\section{Design of Course and Assignment}

Many colleges and universities offer healthcare ethics courses to audiences of pre-medical students. The Philosophy department at the University of Kentucky offers multiple sections of its healthcare ethics course every semester, and Bursten teaches sections at least once per academic year, on average. Bursten's course integrates orthodox topics in healthcare ethics with training in how specific local populations - primarily Southern U.S. Black communities and rural white Appalachian communities - encounter barriers to accessing healthcare. The course is designed to help students develop practical strategies in ethical reasoning as both users and providers of health care.

Most students in the class are science majors aspiring to medical professional programs, primarily in the non-physician track (pre-nursing, pre-dental, and pre-physician's assistant). Other enrollees include students with career plans in health care law, as well as pharmaceutical research and sales. The course also fulfills a requirement for majors in Family Sciences. There are no prerequisites for the course. Few Philosophy majors enroll (typically 0-1 per section, regardless of section size), and for most students, it is their first and/or only course in Philosophy. Enrollment is typically more than $70 \%$ women, which is unusual for U.S. Philosophy classes and for Philosophy classes at the University of Kentucky. Most students are in their penultimate or final year of undergraduate study. Most students are from Kentucky or the nearby region and plan to pursue careers in this geographic area. A final interesting feature of the student population is that many students report on course intake forms or in homework assignments that they have had alienating experiences with U.S. health care systems, either as patients or as friends and family. In sum, the students enrolling in this course are there for a variety of personal, academic, and professional reasons. Many of these reasons motivate students to be interested in ethical problems in health care systems in Kentucky and the U.S., while fewer motivate them to be interested in the academic practice of philosophy.

The course is designed for this diverse, personally and professionally motivated population. Assignments differ in structure and learning objectives from assignments designed for a population of Philosophy majors. For instance, it is not a goal of the course to teach students how to write an academic philosophy paper, as this is not a highly transferable skill for most of them. Instead, assignments are designed to develop the critical-thinking skills characteristic of 
good philosophical reasoning via activities that are personally relevant and practically applicable. These include a personal-narrative assignment in which students identify and investigate their personal "moral compasses" and apply the results to a boundary case in health care (Bursten and Finkelstein 2018), as well as an assignment in which students identify an ethical problem in Kentucky's healthcare systems and propose a solution.

Because increased understanding of local communities' encounters with local healthcare systems is a goal of the course, and because most students aim to work in-state or in-region, course design includes activities that help students to learn about the state and region's historical and present engagements with healthcare and reflect on how healthcare plays a larger role in the social ecology of the region. In addition to requiring students to identify a statespecific ethical problem in healthcare, students learn about the Tuskegee Syphilis Experiment and read The Immortal Life of Henrietta Lacks, both of which have connections to the Southern U.S., in which Kentucky is located. Local and regional guest-lecturers, such as staff and faculty in the University of Kentucky's hospital system, supplement this learning objective, as does the personal-narrative assignment's task of having students identify how their personal histories have influenced their moral compasses.

Increased understanding healthcare's impact on the social ecology of the region are supported by development of improved skill in critical reasoning and basic comprehension of different ethical theories (Hall, Engebretson, O'Rourke et al. 2017; Lee and Brown 2018), as well as training in fundamental concepts in the philosophy of science, particularly in the impossibility of the value-free ideal in medical research (Kincaid 2007; Douglas 2009; Katikreddi and Valles 2015). These learning objectives all converge in the class's encounter of medical research records in the University of Kentucky's Special Collections. In Section 3, we discuss contemporary changes in thinking about the pedagogical benefits of work with archival materials, and in Section 4, we describe the design of the ABLA that arose from our desire to have these students confront these medical records.

\section{Pedagogy of/in Archives}

Archival collections held at universities and colleges were historically regarded primarily as research tools or signifiers of prestige. However, in the past 20 years, university and college archivists have transitioned into new educational roles within their institutional settings (Daniels and Yakel 2013). ${ }^{1}$ Today it is common to find "Education" "Instruction" or "Outreach" archivists working within academic archives in the U.S. ${ }^{2}$ These professionals focus on building relationships with faculty and instructors in order to increase student access to archival collections. They achieve this goal by planning and delivering instruction sessions and research

\footnotetext{
${ }^{1}$ Yakel and Morgan signal this beginning with the findings of the Boyer Commission Report on Reinventing Undergraduate Education, published in 1998, which advocated for research experiences throughout the undergraduate curriculum.

${ }^{2}$ For instance, all fourteen R1 Research Universities in the Southeastern Conference have archivists or librarians listed in library directories who either use these titles or have outreach or instruction listed in their curatorial or professional responsibilities.
} 
activities, as well as playing a pivotal role in planning major research projects that utilize archives. Even in smaller organizations where a limited team of archivists are responsible for the entire archives, it is now much more common to find archivists dedicating more time to public services and teaching, rather than simply focusing on the more "traditional" role of processing, cataloging, and describing collections.

Because archives, in general, have shifted further toward accessibility and instruction, there are an increasing number of professional archivists who have responsibilities related to education and outreach. Whether solely dedicated to collaborating with faculty members to teach workshops or class sessions or having room for that work in their assigned responsibilities, the availability of archivists to focus on this work has allowed it to blossom and expand in the past decade. These shifts have made it possible for archivists to embed both their presence and their materials as central components of undergraduate courses. The pedagogical innovation of incorporating archival research into undergraduate classes has been shown to improve student learning in the areas of information literacy and critical thinking (Horowitz 2015).

Additional research on the pedagogical benefits of interaction with archives reports a variety of learning advantages. For instance, a recent survey of student learning via archives, Daniels and Yakel (2013) reported that students who interacted with primary sources during their research process experienced (1) increased confidence in their research abilities, (2) increased awareness of archives as a valuable information source, and (3) increased levels of valuing archival materials as central to their learning goals. Similarly, a study by Krause (2010) showed that students who interacted with archives during the course of a history class reported increased skills in observation, interpretation, evaluation, and research skills, as compared with a control group who did not engage with archives.

The shift in professional focus for archivists towards instruction and outreach led to the development of learning guidelines specifically for learning with primary sources. A 2018 joint task force of archivists and professionals from the Society of American Archivists and the Rare Book and Manuscripts Section of the Association for College and Research Libraries developed the Guidelines for Primary Source Literacy (SAA-ACRL/RBMS Joint Task Force on the Development of Guidelines for Primary Source Literacy 2018). Much like existing information literacy standards in other fields, these primary source literacy guidelines provide a template for designing valuable learning experiences that benefit undergraduate and graduate students. They focus on helping students in conceptualizing, finding, reading, analyzing, and using primary sources in their fields of study. The guidelines are a marker of how much primary source literacy and teaching has accelerated over the past ten years.

Archivists and instructors alike have begun to integrate into courses high-impact research experiences that support a stronger connection to theories or topics discussed in class. These experiences led to the creation of primary source literacy guidelines and a formal assessment process. The ABLA discussed in this article was used as a pilot assessment of the pedagogical benefits of archive use at the University of Kentucky. The assessment, conducted by staff at University of Kentucky archives, was based on the 2018 Primary Source Literacy guidelines. It focused on three areas of primary source literacy: 
1. "Critically evaluate the perspective of the creator(s) of a primary source, including tone, subjectivity, and biases, and consider how these relate to the original purpose(s) and audience(s) of the source."

2. "Situate a primary source in context by applying knowledge about the time and culture in which it was created; the author or creator; its format, genre, publication history; or related materials in a collection."

3. "Demonstrate historical empathy, curiosity about the past, and appreciation for historical sources and historical actors."

The results of the assessment for this ABLA form the basis of the discussion of the pedagogical benefits of the activity in Section 5 .

\section{Investigating Medical Research Archives as Ethical Training: Enovid Studies in Kentucky}

In this healthcare ethics ABLA, students investigate files that contain original research-subject records of women living in Eastern Kentucky. Eastern Kentucky is a mountainous region in which Appalachian and Southern U.S. cultures intersect. It is best-known for coal production and is, coincidentally, one of the epicenters of the current opioid epidemic. The present population is rural, predominantly white, and economically depressed. The study subjects participated in early U.S. trials of the hormonal contraception pill, Enovid. (Frontier Nursing Service Medical Surveys, 1996)

Enovid was the first hormonal contraceptive medication approved by the U.S. Food and Drug Administration (FDA). A combined oral contraceptive pill, Enovid was a mestranol/noretynodrel combination that was initially FDA-approved to treat menstrual disorders in 1957 and which was approved for use as a contraceptive in 1960. The same formula was approved as a contraceptive in Canada and the United Kingdom in 1961. With its development championed by controversial figures including feminist activist and eugenicist Margaret Sanger, physician and pharmaceutical tycoon Clarence Gamble, and biologist Gregory Pincus, Enovid has storied roots in both the women's liberation and eugenics movements in the 20th-century U.S. Throughout the 1950s and 1960s, gynecologist John Rock, a colleague of Pincus, conducted trials of Enovid throughout the U.S. and its territories. These began in Brookline, MA, near to Pincus and Rock's places of work. Rock later conducted a famous set of trials on around 200 women in Puerto Rico. Scholars widely recognize these trials as lacking informed consent and as being emblematic of how researchers' disaffected attitudes toward subjects can lead to poor health outcomes for subjects (Briggs 2012). Rock's trials on 156 women in Kentucky followed similar protocols to the Puerto Rican trials, but are much less well-documented in the scholarly literature. This may be due to the restrictions on access to the records, discussed below.

The study records range from 1959-1968 and document personal health information associated with individual research subjects' experiences while taking Enovid, primarily information about menstrual cycles and sexual health. The records were documented by nurses working for the Frontier Nursing Service, a regional healthcare service specializing in providing healthcare to 
rural regions of the state, and participants were incentivized to participate by receiving free doctors' visits during the study. The archive contains 156 individual subjects' records. The records are not blinded. The collection is restricted until 2038 , such that the identification of any names of patients or their place of residence in any manner is prohibited and no part of the collection may be photocopied, microfilmed, digitized, or reproduced in any manner.

To carry out the ABLA, prior to the start of the semester, Bursten and Strandmark designate a class "Special Collections Day" when students will meet in the university's Special Collections Research Center instead of in the usual classroom. In the week prior to Special Collections Day, Bursten distributes an assignment description that advises students on the etiquette and requirements of archival research, outlines the assignment plan, and contains background information on (a) the history of hormonal birth control, including links to episodes of two popular podcasts (Mars 2017, Clark and Bryant 2018), (b) the history of the Frontier Nursing Service, and (c) didactic text from Special Collections' description of the collection that students will access on Special Collections Day. The information in Sections (b) and (c) is developed from Frontier Nursing Service Medical Surveys (1996), while the information in Section (a) is developed from Blakemore (2019), Buttar and Seward (2009), Planned Parenthood Federation of America (2015), and Frontier Nursing Service Medical Surveys (1996). Students are also encouraged to do additional independent research on how hormonal birth control and oral contraceptives work, on health complications associated with early oral contraceptives, and on the intertwined history of birth control and eugenics. Anecdotally, we have noted that around a third of students arrive on Special Collections Day having done some independent background research.

Special Collections Day begins with a general orientation to Special Collections: Strandmark introduces students to the research and learning resources available at Special Collections, provides an overview of features of note in the Collections, and instructs students in how to interact with archives on their own in the future. Strandmark also offers tours of the Special Collections Research Center to students during class.

Before being permitted to access the Enovid records, students receive training on proper care and handling of both the medically confidential information and the half-century old paper material that comprise the archives. Each student signs a permission form to be allowed to view the records. Once they sign permission forms, students are given an assignment questionnaire that is designed to structure their engagement with the archival records.

Next, Bursten splits students into teams of 4-6 based on student last names. Students introduce themselves to their teammates and are encouraged to work together to interpret the records and answer questions in the assignment questionnaire. Representative questions from the ABLA questionnaire are listed in Table 1. Each team receives 5 files to survey and one file to use as a case study. Survey files are paired with survey questions in order to familiarize students with the structure of the archival documents, and case-study files are used to prompt more extensive analysis.

\begin{tabular}{|l|l|}
\hline Question Type & Representative Questions \\
\hline
\end{tabular} 


\begin{tabular}{|c|c|}
\hline \multirow[t]{2}{*}{ Fact Discovery } & $\begin{array}{l}\text { What range of doses (how much medication } \\
\text { per pill) are there in the records you } \\
\text { reviewed? }\end{array}$ \\
\hline & $\begin{array}{l}\text { What is the average amount of time the } \\
\text { women spent in the study, based on the } \\
\text { records you reviewed? }\end{array}$ \\
\hline \multirow[t]{2}{*}{ Critical Reasoning } & $\begin{array}{l}\text { What is the main violation of confidentiality } \\
\text { across the records? }\end{array}$ \\
\hline & $\begin{array}{l}\text { Who is responsible for this violation? How } \\
\text { can you tell? (Note: This is not an } \\
\text { interpretation question. There is a correct } \\
\text { answer to this question.) }\end{array}$ \\
\hline \multirow[t]{2}{*}{ Interpretation } & $\begin{array}{l}\text { Look at the way different record-keepers } \\
\text { describe their subjects (different record- } \\
\text { keepers have different handwriting). Describe } \\
\text { what you see. Are the record-keepers } \\
\text { consistent in the way they report their } \\
\text { subjects' experiences? Are the records } \\
\text { thorough? }\end{array}$ \\
\hline & $\begin{array}{l}\text { Given what you've learned about the } \\
\text { background of the study, why do you think the } \\
\text { study was targeted at women in Leslie } \\
\text { County and surrounding areas? }\end{array}$ \\
\hline Reflection and Disposition & $\begin{array}{l}\text { How would you feel if you had been a subject } \\
\text { in this study and these records were found by } \\
\text { students } 60 \text { years from now? }\end{array}$ \\
\hline \multirow[t]{2}{*}{ Case Analysis } & $\begin{array}{l}\text { This woman was withdrawn from the program } \\
\text { because she died. Is there evidence that her } \\
\text { death was connected to use of Enovid? }\end{array}$ \\
\hline & $\begin{array}{l}\text { What evidence in the record, and what other } \\
\text { information about Enovid and high-dose } \\
\text { estrogen medications, supports your } \\
\text { answers? }\end{array}$ \\
\hline
\end{tabular}

Table 1: Question types and representative questions in healthcare ethics ABLA.

The questionnaire begins by asking students to find answers to basic factual questions about the records, such as the amount of medication administered and the age of the subjects. Next, students answer critical-reasoning questions about the ethical violations in the study. For instance, students are asked to identify a global ethical violation in the study, namely the violation of subject confidentiality, and to use clues from the document structure to determine who is responsible for the violation. Then, students are asked open-ended questions about what moral and ethical inferences they can make based on what they see in the files. Different files 
contain different information, so different teams' answers vary significantly, and they are encouraged to compare across teams.

In the final part of the survey, students are asked questions that prompt reflection on what the experience of the study would have been like from the perspective of a participant and from the perspective of one of the record-keepers. Students are prompted to connect the study to previous lessons about healthcare's role in the social ecology of the region, and about the role of values in guiding the design of medical research. These questions are designed to engage students along a learning dimension commonly referred to as "disposition" or "mindset" learning (Driscoll and Wells 2012). Dispositional learning encourages student development not through the refinement of skills or increase of knowledge, but rather through the cultivation of sensitivity to individual, cultural, and moral contexts, which in turn constrain the application of critical reasoning (see, e.g., Schussler 2006).

After completing the survey, each team analyzes one file that has been selected by Bursten and Strandmark because it contains a specific circumstance or feature of interest. Examples include a subject who withdrew from the trial and restarted, a subject who underwent a surgery, and a subject who died. This case-study analysis is guided by three prompts. First, students are asked to describe what they see in the record, comparing and contrasting it with records in the survey. Next, they answer a case-specific prompt designed to guide them to the feature of interest in the case. Finally, they reflect on whether and to what extent the specific feature of the case is connected to the use of hormonal birth control, to the region's healthcare settings, or to the treatment of women in U.S. healthcare systems in the 1960s.

Students work and discuss the questionnaire prompts in teams throughout the survey and analysis, and we have observed that around one third of teams take it upon themselves to exchange contact information to continue discussing the assignment outside of class time. Students turn in individual reports a week after Special Collections Day. They are encouraged to return to Special Collections on their own during the intervening week if they need to gather additional information, or if they are ill or otherwise absent during Special Collections Day, but only 1-2 students per semester typically avail themselves of this opportunity.

Students engage with archival materials, and with the archival space of Special Collections, in a number of ways throughout the ABLA: they attend class in the archive space, they tour the space and receive training in how to access archival material on their own in the future, and they receiving training in handling archival materials and then handle the materials. The ABLA is designed to create an experience that imitates certain affective features of "genuine" archival research - the disorientation of confronting historical documents and trying to figure out what they mean, the excitement of connecting the dots between pieces of information in an archival material, etc. - in a highly scaffolded environment where success is nearly guaranteed. A disadvantage of this approach is that it does not create room for the affective experience, common in genuine archival research, of digging for days or weeks with nothing to show. As we discuss below, we believe that there are nonetheless significant benefits to interacting directly with archival materials even in this highly scaffolded manner. We thank an anonymous reviewer for pressing us on this point. 


\section{Outcomes and Discussion: The Pedagogical Significance of Touching History}

In this section, we reflect on the success and limitations of this ABLA and suggest some mechanisms that may explain our observations of student learning experiences. Student feedback in this section is drawn from the pilot assessment described in Section 3. The qualitative, content-driven questions from that assessment are reproduced in Table 2. Students were also asked basic demographic questions. The assessment was completed by 50 students from Bursten's Fall 2019 Healthcare Ethics class. Our discussion is supplemented by observations of students' ABLA reports from Fall 2016-Fall 2019.

The assessment focused on student experiences in four areas: (1) understanding the biases present in the records, (2) understanding the influence of cultural context, (3) understanding why these records were preserved, and (4) understanding their impact on their study of healthcare ethics. Qualitative student feedback also connects more broadly to the pedagogical motivations behind integrating ABLAs into undergraduate courses, which were discussed in Section 3.

Explain any biases that you noticed in the medical surveys or patient files.

Think about the setting and location of this study. How did the historical or cultural context of these communities influence the study?

Why was it important to save and preserve these records? How did they help you learn about health care and medical ethics?

Overall, did you find the class session in Special Collections helpful to the development of your skills as a student/researcher?

Please explain your answer - why Yes or No?

What did you like about the session? What did you learn?

In your opinion, how could the session be improved?

Table 2: Survey questions from Special Collections' assessment of healthcare ethics ABLA.

When examining the bias prevalent in the medical surveys and patient files, students repeatedly pointed out the neglect of research subject welfare by the administering healthcare professionals. Students noticed that the researchers tended to list the more positive aspects of the drug, and glossed over any negative side effects. Students picked up on the lack of personal care given to the women involved in the study, which led students to believe that the doctors involved were much more concerned with appeasing the administrators of the study rather than caring for their patients.

The notable feature of these reflections is the students' identification of the researchers and record-keepers as human agents responsible for moral decision-making. This is an example of 
the ABLA bringing abstract concepts, such as the ethical treatment of human research subjects, into concrete focus by anchoring the philosophical idea in a historical setting. We believe that this learning was further enhanced by having the setting be local to the University of Kentucky's geographic region, which brought the stakes of the researchers' decision-making into a more tangible, local setting. Some students in the class grew up in the county in which the research took place, and in their assessment answers and their ABLA reports, they wrestled with the idea of seeing their friends and family members as research subjects, and seeing their local physicians' offices as settings for medical research.

Through guided prompts in the assignment questionnaire, students also learned to "read between the lines" in the records. They reported that researchers seemed disinterested in recording side effects or symptoms in detail, and that there was a general lack of uniformity in how this information was recorded. Students sensed that the researchers responsible for surveying the women who participated in the study were disinterested in keeping detailed medical records. They also noted the lack of scientific uniformity in the record-keeping, which would be expected for a study of this magnitude. In their ABLA reports, some students noted this unevenness as a source of systematic bias in the research that was being developed.

It is our hope that students recall these observations to mind in their professional encounters with medical record-keeping and use this research experience to inform their dispositions toward medical patients and medical research subjects. While we have no metric by which to measure whether that hope is realized, the theory of dispositional learning suggests that when students interact with a learning object, such as an archival medical record, building a personal connection in the ways suggested here can reinforce and shape the critical-reasoning lessons learned (Schussler 2006; Stooksberry, Schussler and Bercaw 2009).

Students also observed that record-keepers seemed to be judgmental or disrespectful about the moral choices or intelligence of the women they were interviewing. Students noticed subjectivity and even rudeness in the ways information was recorded by the researchers. They also saw many of the recorded comments as judgemental, and noticed a negative bias toward these women and their personal lives. We believe that these observations indicate students' increased understanding of the interpersonal nature of medical research record-keeping. This connection was referenced in future class units on science and values, which concerned the ways in which bias influences medical research.

The social context of the study further influenced the students' understanding of the archival records. The study's sponsor selected its particular regional setting in part due to the relative lack of access to effective healthcare or family planning methods in Eastern Kentucky. Students noted how this aspect of the study's cultural contexts influenced research design. For example, students noted that the high pregnancy rates and lower rates of literacy and education in this region led the women in the study to both be more open to trying new birth control medication, and to be less aware of the potential risks involved in participating in the study. Interestingly, some students also pointed out that participating in the study, medically dangerous as it may have been, was a form of silent protest against the social norms present in these rural 
communities. Students saw this participation as one way for the women involved to take back control of their own bodies and to defy traditional roles.

When students were asked to reflect on the importance of preserving these records, and how they influenced the way in which they learned about healthcare ethics, their responses were insightful and in line with the research about learning with primary sources discussed in Section 3. For instance, one student wrote that these records served as a reminder of the imperfection of medicine and science. They noted that it is important to recognize and acknowledge past mistakes in order to avoid making similar missteps in the future. Another noted that these records also helped them learn more about Kentucky as a region that they are part of as a community of scholars.

Many of these comments support our view that the ABLA improved students' abilities to reason critically about medical records and doctor-patient relationships through increased connection to concrete pieces of local history. Students used the activity to better understand that the ways in which health care providers administer and document care actually does matter in substantial ways.

A final group of student responses noted how the experience of interacting with the medical records as concrete, tangible objects impacted the learning experience. One student noted that being able to physically touch and connect with the files made the experience more meaningful and impactful. Others said the ABLA was useful because it allowed them to build their skill in interpreting and synthesizing raw, unfiltered records in ways that are not normally possible through reading articles, or in a class textbook. Being thrust into the arena of archival research pushed the students to develop and sharpen their critical thinking and primary source interpretation skills. These responses support our hypothesis that part of what made this ABLA successful was the ability of contextual elements of the archive experience to change the stakes of engagement for students.

This discussion of the students' pilot-assessment responses underscores the value of this ABLA as a philosophy teaching tool. The responses also show how archives-based activities can support learning in non-history subject areas, and in particular how ABLAs can succeed as tools for teaching lessons in philosophy of science to pre-medical students. We hope that when our students become healthcare professionals, they will engage in more careful moral and philosophical reasoning about patient care as a result of their participation in this project.

\section{Conclusions}

In this article, we have described an archives-based learning activity implemented in a healthcare ethics class for pre-medical students. We have highlighted some relevant features of our lesson design that we believe can guide future uses of archives as resources for teaching additional lessons in philosophy of science to non-philosophy majors. We have also given some background on how college and university archives are taking on new educational roles within their institutional settings. Our aim throughout has been to suggest reasons why philosophers of 
science, who are often experienced in archival research, might look to archives as a teaching tool in their classes for non-philosophy majors.

Other recent examples of undergraduate student engagement with archives further break away from the perception that these experiences are only useful for traditional history or related humanities courses. In one case, the students of a Microbial Genetics and Physiology course worked with an archivist to examine and analyze historical materials and rare books that documented the historical progress in understanding and documenting diseases (Brown, Losoff and Hollis, 2014). Other instructors have even devised ways to teach abstract mathematical principles and computer science through historical primary sources (Barnett, Lodder, Pengelley, Pivkina and Ranjan, 2008).

These recent examples show the flexibility of archival materials when developing new pedagogical strategies. Faculty-archivist collaborations can use primary sources as valuable tools for illustrating major trends or driving home key concepts in engaging and interesting ways. Strengthening relationships between faculty members and archivists can generate or improve these activities. These relationships ensure that archivists are not just "tacked on" to existing courses but are truly embedded and tied into the overall goals of the course. For many collaborations, the work begins as a one-off student experience but quickly grows to become a central tenet of the course. Gray (2020) describes one such example: a 12-year collaboration between an archivist and history faculty member at Vanderbilt University. This began with a single session, and has now expanded to undergraduate students spending 10 weeks embedded in the university archives.

We close with a more speculative final reflection on the value of teaching philosophy of science lessons through ABLAs. In developing and implementing this activity, both authors experienced, and witnessed the students experiencing, a keen sense of place associated with interaction with archival materials. We have alluded to this experience throughout our discussion. This sense of place is also experienced as the sensation of touching the past or bringing history to life, or transporting students into another time and place. In our ABLA, student experience of this sensation occurred in two separate, interrelated ways. The first occurred through the experience of interaction with concrete, physical objects from the past: touching records that had been touched by residents of Kentucky half a century prior. This lended gravity to the experience of thinking critically about the record-keepers' actions and choices. The second occurred through the experience of interacting with local records from the recent past, which concretized the experience in a different way, by reminding students that their communities were the ones impacted by this historical research.

Our ABLA grounded student experience in their local environment and tied the history they are currently making to the generations who have come before, or to the ways in which the local environment has shaped their collective futures. We believe that undergoing an experience like this can enable students to better appreciate the historical contingency underlying the development of science, which is often a difficult lesson to impart during a philosophy of science course. Both the historical and practice turns in the philosophy of science are best understood through particular case studies of the development of sciences, as are certain science-and- 
values lessons about the impact of social systems and social values on scientific research. In such cases, we believe that ABLAs can provide a meaningful, concrete, and tangible pathway for students to better comprehend and connect to abstract topics in the philosophy of science.

\section{References}

Barnett, Janet, Jerry Lodder, David Pengelley, Inna Pivkina, and Desh Ranjan. 2008. Designing student projects for teaching and learning discrete mathematics and computer science via primary historical sources. HPM Group Satellite Meeting of ICME, Mexico City, Mexico, July 1418, 2008.

Beam, Carey and Carrie Schwier. 2018. Learning in Place: The Teaching Archivist and PlaceBased Education, Archival Issues 29(1): 17.

Blakemore, Erin. 2019. The First Birth Control Pill Used Puerto Rican Women as Guinea Pigs. https://www.history.com/news/birth-control-pill-history-puerto-rico-enovid

Briggs, Laura. 2012. The Pill in Puerto Rico and Mainland United States: Negotiating Discourses of Risk and Decolonization. In Reed, Lori and Paula Saukko, eds., Governing the Female Body: Gender, Health, and Networks of Powers. Albany, NY: State University of New York Press.

Brown, Amanda, Barbara Losoff, and Deborah R. Hollis. 2014. Science Instruction Through the Visual Arts in Special Collections, Portal: Libraries and the Academy 14(2): 203.

Bursten, Julia R.S. and Finkelstein, Samantha. Promoting Cognitive Conflict In Health Care Ethics: Moral Reasoning With Boundary Cases. In Cukurova, Mutlu, Jane Hunter, Wayne Holmes, and Vania Dimitrova, eds., Practitioner and Industrial Track Proceedings of the 13th International Conference of the Learning Sciences(ICLS18). University College London, London, UK (23-27 June).

Buttar, Aliya and Sheraden Seward. 2009. Enovid: The First Hormonal Birth Control Pill. Embryo Project Encyclopedia. https://embryo.asu.edu/pages/enovid-first-hormonal-birth-controlpill

Clark, Josh and Chuck Bryant. 2018. How the Pill Changed the World. Stuff You Should Know 1069 (19 June 2018). https://www.iheart.com/podcast/105-stuff-you-should-know26940277/episode/how-the-pill-changed-the-world-29483868/

Daniels, Morgan and Elizabeth Yakel. 2013. Uncovering Impact: The Influence of Archives on Student Learning. The Journal of Academic Librarianship 39: 420.

Douglas, Heather. 2009. Science, Policy, and the Value-Free Ideal. Pittsburgh: University of Pittsburgh Press. 
Driscoll, D. L., and J. Wells. 2012. Beyond Knowledge and Skills: Writing Transfer and the Role of Student Dispositions. In Composition Forum (Vol. 26). Association of Teachers of Advanced Composition.

Eig, J. (2016). The birth of the pill: How four pioneers reinvented sex and launched a revolution. Pan Macmillan.

Frontier Nursing Service Medical Surveys (1959-1971) Didactic Text. 1996. 96M8, Special Collections Research Center, University of Kentucky. Available at https://exploreuk.uky.edu/fa/findingaid/?id=xt7c862b9k4x\#fa-heading-abstract

Gray, Teresa. 2020. "Special Collections in the Classroom: Embedding Special Collections in an Undergraduate History Writing Class," Public Services Quarterly 16(2): 139.

Hall, T.E., Engebretson, J., O’Rourke, M. et al. 2017. The Need for Social Ethics in Interdisciplinary Environmental Science Graduate Programs: Results from a Nation-Wide Survey in the United States. Science and Engineering Ethics 23: 565-588.

Horowitz, Sarah. 2015. Hands-On Learning in Special Collections: A Pilot Assessment Project, Journal of Archival Organization 12(3-4): 228.

Katikireddi, S. and S. Valles. 2015. Coupled Ethical-Epistemic Analysis of Public Health Research and Practice: Categorizing Variables to Improve Population Health and Equity. American Journal of Public Health 105: e36-e42.

Kincaid, Harold. 2007. Contextualist morals and science. Pp. 218-238 in Kincaid, Harold, John Dupre, and Alison Wylie, eds., Value-Free Science? Ideals and Illusions. Oxford: Oxford University Press.

Krause, Magia. 2010. Undergraduates in the Archives: Using an Assessment Rubric to Measure Learning. The American Archivist 73(2): 507-534.

Lee, E.A. and M.J. Brown. 2018. Connecting Inquiry and Values in Science Education. Science \& Education 27: 63-79.

Liao, P. and J. Dollin. 2012. Half a century of the oral contraceptive pill: historical review and view to the future. Canadian family physician Medecin de famille canadien, 58(12): e757-e760.

Mars, Roman. 2017. Repackaging the Pill. 99\% Invisible 266 (10 July 2017).

https://99percentinvisible.org/episode/repackaging-the-pill/

Planned Parenthood Federation of America. 2015. The Birth Control Pill: A History. https://www.plannedparenthood.org/files/1514/3518/7100/Pill History FactSheet.pdf

SAA-ACRL/RBMS Joint Task Force on the Development of Guidelines for Primary Source Literacy. 2018. Guidelines for Primary Source Literacy.

Schussler, Deborah. 2006. Defining Dispositions: Wading Through Murky Waters, The Teacher Educator, 41:4, 251-268. 
Sharron, D. and J. Cotton. 2011. Engaging Students with Archival and Digital Resources. United Kingdom: Elsevier Science.

Stooksberry, Lisa, Deborah Schussler, and Lynne Bercaw. 2009. Conceptualizing dispositions: intellectual, cultural, and moral domains of teaching, Teachers and Teaching, 15:6, 719-736. 